\title{
VNG FINDINGS IN PATIENTS WITH AGE RELATED ISCHEMIC CHANGES.
}

\author{
Nagwa Mohamed Abd El-Monem Hazzaa*, Noha Ali Shafik*, \\ Aya Yassin Ahmed Mohamed **and Amany Mohamed Abo El-Khair****
}

\author{
Audiology Unit, Department of \\ Otolaryngeology, * Audio- \\ vestibular medicine, ENT \\ Department, ** Radiology \\ Department, Ain Shams University. \\ *** Audiology resident, ENT \\ Department, Ahmed Maher \\ teaching hospital. \\ Corresponding author \\ Amany M. Abo El.Khair Atea, \\ Mobile: (+2) 01288839857. \\ E.mail: \\ amany.abo.el.khair@gmail.com \\ Received: $16 / 12 / 2020$ \\ Accepted: 11/1/2021
}

Online ISSN: 2735-3540

\begin{abstract}
:
Background: Older people develop gait and balance dysfunction that is associated with gradual onset of cerebral white matter disease. The term cerebral small vessel disease refers to a group of pathological processes with various etiologies that affect the small arteries, arterioles, venules, and capillaries of the brain. White matter disease is easily detected by neuroimaging, whereas small vessels are not, hence the term small vessel disease is frequently used to describe the parenchyma lesions rather than the underlying small vessel alterations.
\end{abstract}

Aim of the work: To investigate the relationship between presence and/or absence of white matter disease identified on magnetic resonance imaging with the vestibular findings in elderly patients with dizziness.

Patients and Method: Study population: 30 elderly patients complaining of dizziness \& / or instability. Inclusion criteria: Patients above 55 years old with history of vertigo \& / or instability. Exclusion criteria: 1-Meniere's disease. 2- Bilateral vestibulopathy. 3- Recent vestibular neuritis or labyrinthitis. 4- History of head trauma or surgery. 5- Neurological diseases as (Intracranial space occupying lesions, Multiple Sclerosis, Parkinsonism, Paresis). 6- Patients with otologic history of otorrhea or Ear surgery. Study Procedure: 1- Full history taking. 2- Otological examination. 3- Hearing assessment. 4Immittancemetry. 5- Video-nystagmography test (VNG). 6- Magnetic resonance imaging (MRI) \& Magnetic resonance angiography (MRA) "Stroke protocol".

Results: Abnormal VNG test results were significantly higher in patients with atherosclerotic changes (0.04). The most common VNG finding was positional nystagmus.

Conclusion: Presence of risk factors for white matter disease (WMD) in elderly patients as hypertension, diabetes mellitus, ischemic heart disease, hyperlipidemia and migraine is an indication for requesting further radiological assessment. The most frequent $V N G$ abnormality in elderly patients with WMD is positional \& positioning nystagmus. Presence of atherosclerotic changes is significantly related to presence of VNG test abnormality.

Keywords: Dizziness, Age related ischemic disease, white matter disease and Small vessel disease.

\section{INTRODUCTION:}

Dizziness, imbalance and gait disturbance are one of the most common complaints in elderly ${ }^{(1)}$. It is commonly associated with gradual onset of cerebral white matter disease ${ }^{(2)}$. However, the mechanism through which it affects the gait is unknown ${ }^{(3 \& 4)}$. 
White matter disease (WMD) is a radiological term used to describe diffuse white matter changes thought to be related to small vessel disease. Several theories were proposed to explain the mechanism of gait disturbances in the elderly ${ }^{(5)}$. VNG is the gold standard for assessment of dizziness and vertigo in the elderly.

To the best of authors' knowledge, there is limited researches examined the relation between age related ischemic changes as a radiological findings in (MRI \& MRA) and the vestibular findings detected by VNG in elderly patients complaining of dizziness and / or imbalance. Therefore, the present study is designed to evaluate vestibular findings using VNG in elderly patients and its relation to white matter changes detected by magnetic resonance imaging.

\section{AIM OF THE WORK}

To investigate the relationship between presence and/or absence of white matter lesions identified on magnetic resonance imaging with the vestibular findings in elderly patients with dizziness.

\section{PATIENTS AND METHODS}

Study Setting: At audio-vestibular outpatient clinic \& Radiology department in El-demerdash hospital Ain Shams University.

Study Period: From February 2018 to October 2018.

Study population: 30 elderly patients complaining of dizziness and/or instability from the vestibular outpatient clinic Eldemerdash hospital Ain Shams University.
Inclusion criteria: Age group above 55 years old \& positive history of vertigo and/or instability.

Exclusion criteria: Patients diagnosed with known cause for dizziness as Meniere's disease, bilateral vestibulopathy, recent vestibular neuritis or labyrinthitis, history of head trauma or surgery, neurological diseases (Intracranial space occupying lesions, Multiple Sclerosis, Parkinsonism \& Paresis) and patients with otologic history of otorrhea or Ear surgery.

Ethical consideration: The protocol was ethically approved by the ENT department board, the research Ethical Committee, Faculty of Medicine Ain Shams University.

Methods: Each participant underwent: Full neuro-otological history, Hearing assessment: (Otological examination, Pure tone audiometry: (Air conduction thresholds at $0.25,0.5,1,2,4,8 \mathrm{KHz}$, Bone conduction thresholds at $0.5,1,2,4 \mathrm{KHz}$, Speech audiometry and acoustic Immittance testing), Video-Nystagmography Test (VNG) and Radiological assessment: Magnetic resonance Stroke Protocol is a group of magnetic resonance sequences put together to best approach brain ischemia: consists of $\mathrm{T} 1, \mathrm{~T} 2$, T2/FLAIR, diffusion- (DWI) images and MR angiography (MRA) (6,7,8,9\&10). Fazekas classification ${ }^{(11)}$ : It divides the white matter in periventricular (PVWM) and deep white matter (DWM), and is given a grade depending on the size and confluence of lesions on a scale range from (0-3) with the highest grade indicating more severe lesions.

Data Management and Analysis: Data were coded and entered using the statistical package for the Social Sciences (SPSS) version 26 (IBM Corp., Armonk, NY, USA). 


\section{RESULTS:}

Table (1): Mean (X), Standard deviation (SD) and range of age \& gender distribution for the study group:

\begin{tabular}{|c|c|c|c|c|c|c|c|c|}
\hline \multicolumn{3}{|c|}{ Age } & \multicolumn{4}{c|}{ Gender } & \multicolumn{2}{c|}{ Total } \\
\hline X & SD & Range & \multicolumn{2}{c|}{ Male } & \multicolumn{2}{c|}{ Female } & \multicolumn{2}{c|}{} \\
\cline { 4 - 9 } & & $\begin{array}{c}\text { Number } \\
(\text { No. })\end{array}$ & $\begin{array}{c}\text { Percentage } \\
(\%)\end{array}$ & $\begin{array}{c}\text { Number } \\
(\text { No. })\end{array}$ & $\begin{array}{c}\text { Percentage } \\
(\%)\end{array}$ & $\begin{array}{c}\text { Number } \\
(\text { No. })\end{array}$ & $\begin{array}{c}\text { Percentage } \\
(\%)\end{array}$ \\
\hline 65.07 & 7.19 & $55-80$ & 17 & 56.7 & 13 & 43.3 & 30 & 100 \\
\hline
\end{tabular}

Mean age of the study group was 65 and the male $\%$ was higher than the female in the study group.

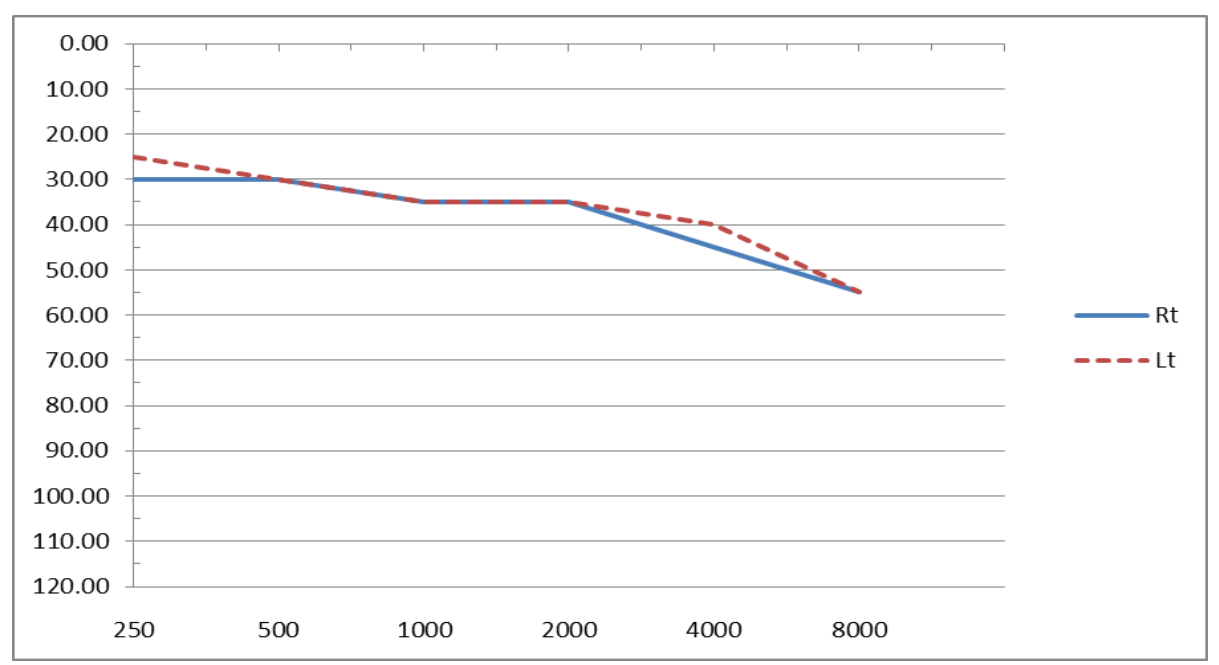

Mean of Pure tone audiometry results of the study group in $\mathrm{dB} \mathrm{HL}$

Table (2): Distribution of patients according to known medical history:

\begin{tabular}{|c|c|c|c|c|}
\hline Risk factors* & \multicolumn{2}{|c|}{ Present } & \multicolumn{2}{c|}{ Absent } \\
\hline & (No.) & $(\%)$ & $($ No.) & $(\%)$ \\
\hline Diabetes & 13 & 43.3 & 17 & 56.7 \\
\hline Hypertension & 16 & 53.3 & 14 & 46.7 \\
\hline Ischemic heart disease & 7 & 23.3 & 23 & 76.7 \\
\hline Hyperlipidemia & 9 & 30.0 & 21 & 70.0 \\
\hline Migraine & 5 & 16.7 & 25 & 83.3 \\
\hline$* *$ Multiple risk factor & 14 & 46.7 & 16 & 53.3 \\
\hline
\end{tabular}

* All patients had at least one risk factor for WMD.

**In some patients, there were multiple risk factors in the same patient.

The table shows that $(46.7 \%)$ of the Hypertension $(53.3 \%)$ and diabetes study group had more than one risk factor. (43.3\%).

The most common risk factors were

Table (3): Distribution of the study group according to site of lesion based on VNG test:

\begin{tabular}{|c|c|c|}
\hline VNG test results & (No.) & $(\%)$ \\
\hline Normal VNG study & 12 & 40 \\
\hline abnormal VNG & 18 & 60 \\
\hline Total patient in study group & 30 & 100 \\
\hline
\end{tabular}

The table shows that $60 \%$ of the study group had abnormal VNG findings. Number of abnormal patients $60 \%$ is lesser than total number of VNG test findings due to presence of multiple test findings in the same patient. 
Table (4): Distribution of patients according to VNG test findings:

\begin{tabular}{|c|c|c|c|c|}
\hline \multirow{2}{*}{ VNG findings } & \multicolumn{2}{|c|}{ No abnormality } & \multicolumn{2}{|c|}{ Abnormal } \\
\cline { 2 - 5 } & $\begin{array}{c}\text { No. of } \\
\text { patients }\end{array}$ & $(\%)$ & $\begin{array}{c}\text { No. of } \\
\text { patients }\end{array}$ & $(\%)$ \\
\hline Spontaneous nystagmus & 26 & 86.7 & 4 & 13.3 \\
\hline Gaze test & 30 & 100 & 0 & 0 \\
\hline Optokinetic & 30 & 100 & 0 & 0 \\
\hline Pursuit & 30 & 100 & 0 & 0 \\
\hline Saccade & 30 & 100 & 0 & 0 \\
\hline *Positioning & 25 & 83.3 & 5 & 16.7 \\
\hline **Positional & 17 & 56.7 & 13 & 43.3 \\
\hline$* * *$ Unilateral Caloric weakness & 26 & 86.7 & 4 & 13.3 \\
\hline
\end{tabular}

N.B.: No isolated central vestibular deficit was detected in the study group. Some patients had multiple VNG abnormality.

All the patients in the study group showed no abnormality in the occulomotor tests and the most frequently encountered VNG abnormality was the presence of positional nystagmus.

*There was abnormality in positioning test in 5 patients 3 of them had in addition to the positioning nystagmus either spontaneous and / or positional nystagmus (of mixed peripheral and central criteria of vestibular lesion) as following; (vertical nystagmus, one of them diminished while others abolished or diminished with fixation, with minimal subjective sense of dizziness).

**The other patients with positional nystagmus were either peripheral with the following criteria; (horizontal nystagmus, directional fixed, abolished with fixation \& with subjective sense of dizziness) or mixed Table (5): Distribution of patients according to different radiological findings:

\begin{tabular}{|c|c|c|c|c|c|c|}
\hline & \multicolumn{2}{|c|}{ Present } & \multicolumn{2}{c|}{ Absent } & \multicolumn{2}{c|}{ *Total } \\
\hline & No. & $\%$ & No. & $\%$ & No. & $\%$ \\
\hline Involution brain changes & 15 & 53.6 & 13 & 46.4 & 28 & 100 \\
\hline White matter disease & 22 & 78.6 & 6 & 21.4 & 28 & 100 \\
\hline Old multi lacunar infarction & 12 & 42.9 & 16 & 57.1 & 28 & 100 \\
\hline Atherosclerotic changes & 20 & 71.4 & 8 & 28.6 & 28 & 100 \\
\hline Mixed lesion** & 22 & 78.57 & 6 & 21.42 & 28 & 100 \\
\hline
\end{tabular}

* Two patients were excluded from 30 patients due to contraindication of MRI due to metallic heart prosthesis and metallic clips, so the total radiological investigated patients were 28 . peripheral and central criteria of vestibular lesion as following; (vertical nystagmus, abolished or diminished with fixation with minimal subjective sense of dizziness). Among the study group, $13.3 \%$ of the patients had non localizing positional nystagmus based on the presence of positional nystagmus as the only VNG finding with the criteria of positional nystagmus not clearly matching a peripheral or central site of lesion (vertical nystagmus, abolished or diminished with fixation with minimal subjective sense of dizziness).

$* * * 13.3 \%$ of the study group had unilateral caloric weakness 2 of them were uncompensated as accompanied with spontaneous or positional nystagmus and the other 2 were compensated with the unilateral caloric weakness as the only VNG finding. 
Table (6): Distribution of the patients according to Fazekas Scoring:

\begin{tabular}{|c|c|c|c|c|c|c|c|c|c|c|c|}
\hline \multicolumn{2}{|c|}{ PVWM 0} & \multicolumn{2}{|c|}{ PVWM 1} & \multicolumn{2}{|c|}{ PVWM 2} & \multicolumn{2}{|c|}{ PVWM 3} & \multicolumn{2}{|c|}{ Total } & \multirow{2}{*}{\multicolumn{2}{|c|}{ PVWM+DWM }} \\
\hline No & $\%$ & No & $\%$ & No & $\%$ & No & $\%$ & No & $\%$ & & \\
\hline 8 & 28.6 & 4 & 14.3 & 4 & 14.3 & 12 & 42.9 & 28 & 100 & No & $\%$ \\
\hline \multicolumn{2}{|c|}{ DWM 0} & \multicolumn{2}{|c|}{ DWM 1} & \multicolumn{2}{|c|}{ DWM 2} & \multicolumn{2}{|c|}{ DWM 3} & \multicolumn{2}{|c|}{ Total } & & \\
\hline No & $\%$ & No & $\%$ & No & $\%$ & No & $\%$ & No & $\%$ & 19 & 67.9 \\
\hline 7 & 25 & 5 & 17.9 & 6 & 21.4 & 10 & 35.7 & 28 & 100 & & \\
\hline
\end{tabular}

The table shows that the most common Fazekas scorings in the study group are grade 3 WMD; Periventricular white matter (PVWM) \& Deep white matter (DWM) and combined lesion of both PVWM \& DWM.

Table (7): Chi square test between VNG test results \& different radiological findings:

\begin{tabular}{|c|c|c|c|c|c|c|}
\hline & & \multicolumn{4}{|c|}{ VNG results } & \multirow{2}{*}{$P$ value } \\
\hline & & \multicolumn{2}{|c|}{ Normal } & \multicolumn{2}{|c|}{ Abnormal } & \\
\hline & & No. & $\%$ & No. & $\%$ & \\
\hline \multirow{2}{*}{ Atherosclerotic changes } & Yes & 6 & $50.0 \%$ & 14 & $87.5 \%$ & \multirow{2}{*}{0.044} \\
\hline & No & 6 & $50.0 \%$ & 2 & $12.5 \%$ & \\
\hline \multirow{2}{*}{ Old lacunar inf. } & Yes & 4 & $33.3 \%$ & 8 & $50.0 \%$ & \multirow{2}{*}{0.378} \\
\hline & No & 8 & $66.7 \%$ & 8 & $50.0 \%$ & \\
\hline \multirow{2}{*}{ WMD } & Yes & 9 & $75.0 \%$ & 13 & $81.3 \%$ & \multirow{2}{*}{1} \\
\hline & No & 3 & $25.0 \%$ & 3 & $18.8 \%$ & \\
\hline \multirow{2}{*}{ Involution brain changes } & Yes & 7 & $58.3 \%$ & 8 & $50.0 \%$ & \multirow{2}{*}{0.662} \\
\hline & No & 5 & $41.7 \%$ & 8 & $50.0 \%$ & \\
\hline
\end{tabular}

The table shows that the presence of atherosclerotic changes as a finding detected by MRA was statistically significantly higher in patients having abnormal VNG test findings ( $\mathrm{P}$ value $=0.04$ ).

\section{DISCUSSION:}

In the present work, the authors are demonstrating the vestibular results of 30 dizzy patients in addition to their radiological findings. In 25 of them no clear etiological diagnosis could be reached after full history taking and VNG testing (5 patients had BPPV) (Table 4).

The most common risk factors for WMD in the present study were hypertension $(53.3 \%)$ and diabetes mellitus (43.3\%). Other risk factors included, hyperlipidemia (30\%), ischemic heart disease $(23.3 \%)$, migraine $(167 \%)$ and $46.7 \%$ of the study group had more than one risk factor (Table 2).

Other study also found that arterial hypertension was found to be the most common risk factor of the dizziness associated white matter disease in elderly patients with a percentage of $81 \%{ }^{(12)}$. Cardiovascular factors also could have a pathogenic role in WMD as well as in vestibular disorders and in aggravating symptoms of both diseases ${ }^{(12)}$.

The value of the present work can be looked for from two prospective; first is the normal VNG test results in $40 \%$ of patients. In cases of elderly "or adults above age of 55 years" testing shouldn't stop at this stage. All subjects in this group (including the 40 $\%$ normal VNG) (Table 3 ) had one or more radiological abnormality as detected by MRI and/ or MRA (Table 5).

Furthermore, the $50 \%$ of normal VNG subjects had atherosclerotic changes as detected by MRA compared to $87.5 \%$ of the abnormal VNG group (Table 7). Chi square test results showed a statistically significant difference $(\mathrm{P}$ value $=0.044)$. Elderly dizzy patients with normal VNG findings who have more risk factors for WMD as diabetes or hypertension should be subjected to radiological studies to receive appropriate medical treatment if needed. 
Another interesting finding in the present work is the normal occulomotor test results in all subjects (Table 4). Contrary to the present study, another study found that there was positive predictive value of abnormal occulomotor test findings in relation to magnetic resonance imaging abnormalities. Compared to the present work, their group included cortical and cerebellar atrophy subjects' accordingly central vestibular lesion and abnormal occulomotor abnormalities can be expected $^{(14)}$.

Moreover, occulomotor abnormalities are often accompanied by CNS diseases with symptoms such as blurred vision, oscillopsias, double vision or staggering ${ }^{(15)}$. Such conditions were among the exclusion criteria in the present study.

Concerning subjects with abnormal VNG findings, $60 \%$ of the study group showed vestibular abnormality. This agreed with another study who found that there was a higher prevalence of pathological vestibular signs in patients with $\mathrm{WMD}^{(16 \& 17)}$. Also, BPPV was found to be the main cause of the dizziness in $26 \%$ of patients with WMD (Fazekas 2-3) ${ }^{(17)}$.

In the present study, the most frequent VNG abnormality was the presence of positional nystagmus in $43.3 \%$ of patients (Table 4). In the present authors' experience, the presence of positional nystagmus of non-localizing character as "the only anomaly in VNG" is almost always related to the presence of age related ischemic changes ${ }^{(18)}$. In fact peripheral vestibular involvement or CNS involvement may provide similar finding during testing. The delineation between peripheral and central site of lesion within the vestibular system based on the criteria of positional nystagmus alone should be avoided. It was reported that positional tests could evaluate the state of cerebral perfusion contralateral to the direction of head movement ${ }^{(19)}$. In agreement with the present results, it was reported that Lack of fixation suppression of positional nystagmus supports CNS involvement, but it is also not uncommon for some suppression to occur. Both agerelated CNS changes and migraine may be the cause of positional nystagmus. They also reported an imperative need for correlation with patient history and symptoms, in addition to results of VNG and other diagnostic evaluation $^{(20)}$.

In the present study 5 patients had BPPV, 2 of them had the disease diagnosed by positioning Dix Hallpike test alone while the rest of this group (3 subjects) had in addition positional nystagmus (Table 3 ).

The clinical implication of these findings in patients with BPPV is remarkable. Full VNG test battery is recommended in persistent dizziness after successful repositioning maneuver. The underlying cause of such dizziness may be due to the presence of combined condition as WMD. In the latter case neurological consultation, radiological assessment and medical treatment are warranted.

The most common radiological findings among the study group were white matter disease (WMD) (78.6 \%), atherosclerotic changes $(71.4 \%)$ (Table 5). Periventricular white matter Fazekas score 3 (PVWM 3) was found in $42.9 \%$ and Deep white matter Fazekas score 3 (DWM 3) was found in $35.7 \%$ reflecting the degree of severity of WMD in the dizzy patients (Table 6). Combined lesions (Both PVWM \& DWM) were also very prevalent $(67.9 \%)$ regardless of severity.

Conducting statistical analysis of the present data showed that presence of atherosclerotic changes detected by MRA was associated with higher percentage of VNG abnormalities ( $\mathrm{p}$ value $=0.04)$ (Table 7). It is reported that the cause of this correlation between dizziness induced gait abnormality and WMD could be the disruption of neuronal networks that mediate 
higher vestibular cortical function ${ }^{(12)}$. Also a systematic review indicated that WMD are common in older people and are significantly associated with impaired balance, gait, mobility and falls. However, in many studies these findings were only evident in people who have the most severe degree of $\mathrm{WMD}^{(21)}$.

Moreover, small vessel disease SVD is a dynamic and highly variable disease process with progression and in some regression of $\mathrm{SVD}^{(22 \& 23)}$. In a recent study reduction in blood pressure was associated with reduction in WMD volume ${ }^{(23)}$. This suggests that better blood pressure control could attenuate or even reverse the WMD growth and consequently could lead to better gait function over time.

Age related ischemic changes as a disease prevalent among older adults present with various degrees of dizziness and gait impairment. Dizzy patients with no clear etiology above age of 55 years old have radiological signs of white matter disease with variable degrees of severity and different radiological presentations.

The present results suggest that elderly patients with dizziness, without a clear diagnosis and despite clinical and vestibular assessment, should undergo brain imaging to assess the level of WMD and possible co morbid condition as presence of atherosclerotic changes.

\section{Conclusions:}

Presence of risk factors of white matter disease (WMD) as hypertension, diabetes mellitus, ischemic heart disease, hyperlipidemia and migraine is a medical indication for requesting further radiological assessment in dizzy patients. The most frequent VNG abnormality in elderly patients with white matter disease is positional \& positioning nystagmus. Presence of atherosclerotic changes is significantly related to presence of VNG test abnormality.

\section{REFERENCES:}

1. Iwasaki S \& Yamasoba T (2015): Dizziness and imbalance in the elderly: Age-related decline in the vestibular system. Aging and Disease. International Society on Aging and Disease (Vol.6, pp. 38).

2. Whitman G T, Tang T, Lin A \& Baloh R W (2001): A prospective study of cerebral white matter abnormalities in older people with gait dysfunction. Neurology, 57(6), 990-994.

3. De Laat KF, Tuladhar AM, Van Norden AGW, Norris DG, Zwiers MP \& De Leeuw FE (2011): Loss of white matter integrity is associated with gait disorders in cerebral small vessel disease. Brain, 134(1), 73-83.

4. Rosario B, Rosso A, Aizenstein H, Harris T, Newman A, Satterfield S, Studenski S, Yaffe K, Rosano C (2016): Cerebral white matter and slow gait: Contribution of hyperintensities and normal-appearing parenchyma. Journals of Gerontology - Series A Biological Sciences and Medical Sciences, 71(7), 968-973.

5. Kaski D, Rust H M, Ibitoye R, Arshad Q, Allum J H J \& Bronstein A M (2019, January): Theoretical framework for "unexplained" dizziness in the elderly: The role of small vessel disease. In Progress in Brain Research (Vol. 248, pp. 225-240). Elsevier B.V.

6. Schellinger $\mathrm{P}$ D, Jansen $\mathrm{O}$, Fiebach $\mathrm{J} \mathrm{B}$, Hacke W \& Sartor K (1999): A standardized MRI stroke protocol: Comparison with $\mathrm{CT}$ in hyperacute intracerebral hemorrhage. Stroke, 30(4), 765-768.

7. Wintermark M, Albers G, Alexandrov A, Alger J, Bammer R, Baron J, Davis S, Demaerschalk B, Derdeyn C, Donnan G, Eastwood J, Fiebach J, Fisher M, Furie K, Goldmakher G, Hacke W, Kidwell C, Kloska S, Köhrmann M, Koroshetz W Lee $\mathrm{T}$, Lees $\mathrm{K}$, Lev $\mathrm{M}$, Liebeskind $\mathrm{D}$, Ostergaard L, Powers W, Provenzale J, Schellinger P, Silbergleit R, Sorensen A, Wardlaw J, Wu O \& Warach S (2008): 
Acute stroke imaging research roadmap. In American Journal of Neuroradiology. Vol. 29 (5).

8. Allen L M, Hasso A N, Handwerker J \& Farid H (2012): Sequence-specific MR imaging findings that are useful in dating ischemic stroke. Radiographics, 32(5), 1285-1297.

9. Srinivasan A, Goyal M, Al Azri F \& Lum C (2006, October): State-of-the-art imaging of acute stroke. Radiographics. (Vol.26, 1).

10. Kim A C, Vu D, Gilberto González R \& Schaefer P W (2006): Conventional MRI and MR angiography of stroke. In Acute Ischemic Stroke: Imaging and Intervention (pp. 123144). Springer Berlin Heidelberg.

11. Fazekas F, Chawluk J B, Alavi A, Hurtig H I \& Zimmerman R A (1987): MR signal abnormalities at $1.5 \mathrm{~T}$ in Alzheimer's dementia and normal aging. American Journal of Neuroradiology, 8(3), 421-426.

12. Gamba P \& Pavia M (2016): White matter lesions and vascular vertigo: clinical correlation and findings on cranial magnetic resonance imaging. European Review for Medical and Pharmacological Sciences, 20(13), 2786-2791.

13. Pinter D, Ritchie S, Doubal F, Gattringer T, Morris Z, Bastin M, Hernández M, Royle N, Corley J, Muñoz Maniega S, Pattie A, Dickie D, Staals J, Gow A, Starr J, Deary I, Enzinger C, Fazekas F \& Wardlaw J (2017): Impact of small vessel disease in the brain on gait and balance. Scientific Reports, 7, 41637.

14. Mankekar G, Jeha G, Erbele I, Klumpp M, Sevy A, Mehta R \& Arriaga MA (2019): Do central vestibular findings predict abnormal findings on magnetic resonance imaging? Journal of Laryngology and Otology, 133(7), 554-559.

15. Strupp M, Hüfner K, Sandmann R, Zwergal A, Dieterich M, Jahn K \& Brandt T (2011): Central Oculomotor Disturbances and
Nystagmus. Deutsches Aerzteblatt Online. 108(12): 197-204.

16. Cerchiai N, Mancuso M, Navari E, Giannini N \& Casani A P (2017): Aging with cerebral small vessel disease and dizziness: The importance of undiagnosed peripheral vestibular disorders. Frontiers in Neurology, 8(JUN).pp.241.

17. Ahmad H, Cerchiai N, Mancuso M, Casani A P \& Bronstein A M (2015): Are white matter abnormalities associated with "unexplained dizziness"? Journal of the Neurological Sciences, 358(1-2), 428-431.

18. Hazzaa N (2018): VNG findings in patients with age related ischemic changes. Personal communication.

19. Thomas L \& Treleaven J (2020): Should we abandon positional testing for vertebrobasilar insufficiency? Musculoskeletal Science and Practice, 46. (2468-7812).

20. Shephard N \& Telian S (1996): Electronystagmography evaluation. In Practical management of the balance disorder patient (pp. 51-84). San Diego, CA: Singular.

21. Zheng JJJ, Delbaere K, Close JCT, Sachdev PS \& Lord SR (2011, July): Impact of white matter lesions on physical functioning and fall risk in older people: A systematic review. Stroke. 42:2086-2090.

22. Van Leijsen E, Van Uden I, Ghafoorian M, Bergkamp M, Lohner V, Kooijmans E, Van Der Holst H, Tuladhar A, Norris D, Van DIjk E, Rutten-Jacobs L, Platel B, Klijn C \& De Leeuw F (2017): Nonlinear temporal dynamics of cerebral small vessel disease. Neurology, 89(15), 1569-1577.

23. Wardlaw J, Chappell F, Valdés Hernández M, Makin S, Staals J, Shuler K, Thrippleton M, Armitage P, Munõz-Maniega S, Heye A, Sakka E \& Dennis M (2017): White matter hyperintensity reduction and outcomes after minor stroke. Neurology, 89(10), 1003-1010. 


\section{نتائج اختبار فيديو تخطيط رارأة العين في المرضي الذين يعانون من قصور الاورة الاموية الاماغية} ذات الصئة بالعمر

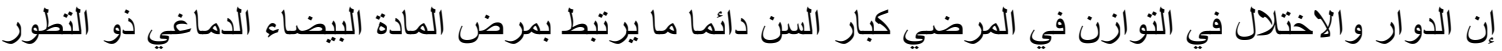

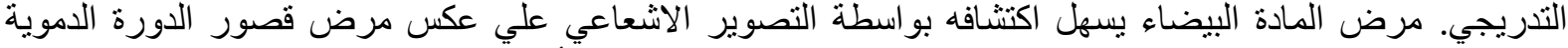
الدماغية الذي دائما ما يشار اليه بالتغيرات في الانسجة بدلا من التغيرات في الأوعية الدموية الصغيرة.

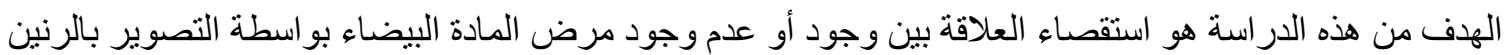
المغناطيسى مع نتائج اختبار ات التوازن بواسطة جهاز فيديو تخطيط رأر أة العين في المرضي كبار السن الذين يعانون من بالئ

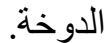

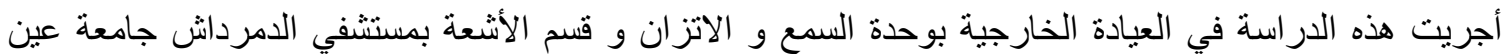

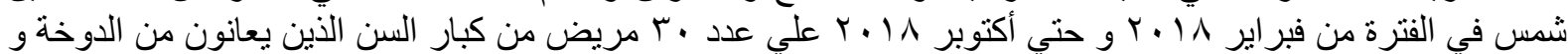

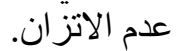

وكانت معايير الادماج هي الفئة العمرية التي تزيد عن

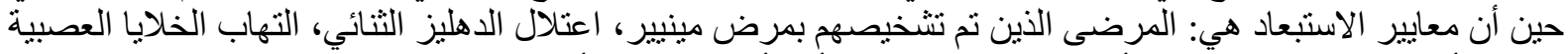

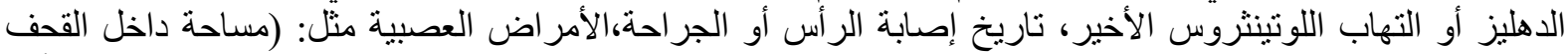

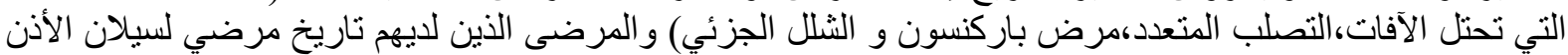

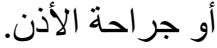

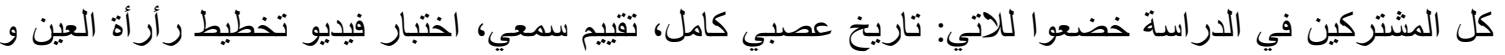

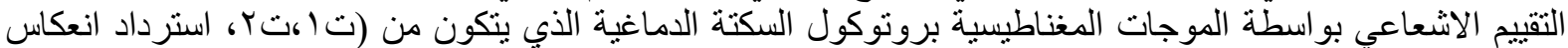

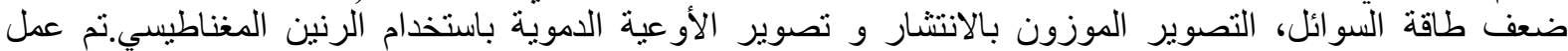
تصنيف فازيكاس للمادة البيضاء الدماغية.

وجود حركات للعين غير طبيعية اثثاء اختبار ات حركات الر اس كان الأكثر تكر ار أ في النتائج الغير طبيعبة لاختبار

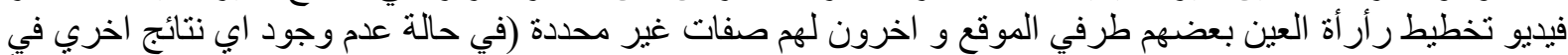

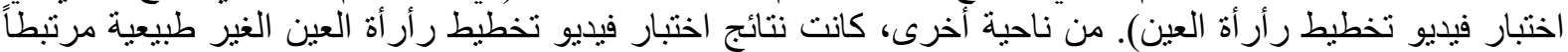

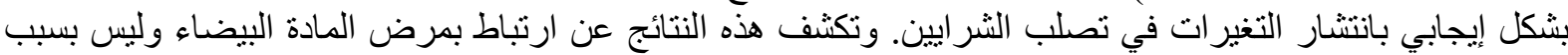

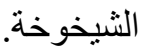
ولهذا السبب يشار إلى التقيبم الإشعاعي للمرضى من كبار السن المصابين بدوار الذين لديهم عو امل مرجحة لمرض المادة البيضاءمنل ارتفاع ضغط الدم، داء النفاء السكري. 